\title{
Sero-prevalence of hepatitis b virus and associated factors among pregnant women's attending antenatal clinics in public hospitals of Hawassa City, Sidama, Ethiopia, 2021. Multicenter cross sectional study
}

Mekonnen Bogale

Hawassa University

Bargude Balta ( $\nabla$ barjuda@gmail.com )

Hawassa University

Research Article

Keywords: Associated factors, sero-prevalence HBV, pregnant women, Hawassa

Posted Date: December 15th, 2021

DOI: https://doi.org/10.21203/rs.3.rs-1112156/v1

License: (c) (1) This work is licensed under a Creative Commons Attribution 4.0 International License.

Read Full License 


\section{Abstract}

Introduction: Estimated 350 million people had been diagnosed for chronic HBV infection and 686,000 people die each year which is an important global public health. This study is expected to provide areaspecific information for decision-makers by visualizing prevalence and its associated factors OF HBV.

Objective: The aim of this study to access prevalence HBV sero-prevalence and associative factors among pregnant women's attending ANC in public hospitals of Hawassa City , 2021.

Method: A analytic cross sectional study was conducted among pregnant women at Public Hospital in Hawassa city from May 20-July 30/2021. A total of 320 participants were selected. Data were entered and analyzed using SPSS version 25.0. Descriptive statics used to determine prevalence of HBV; Bivariate and multivariate logistic regression analysis was done to identify the independent predictors of HBV status at $p$-value $<0.05$. Results:

Results: From total of 320 pregnant women participated in the study twenty two are HBV positive which makes overall prevalence From total of 320 pregnant women participated in the study twenty two are HBV positive which makes overall prevalence $[6.9 \%(95 \%, \mathrm{Cl}(6.6 \%, 7.2 \%))]$. in study area history of transfusion $(A O R=18.99,95 \% \mathrm{Cl},(2.1-171))$. Pregnant women having history of vulvar ulcer were nearly fifteen times more likely to acquire HBV infection comparing having no history of vulvar ulcer (AOR = $14.78 ; 95 \% \mathrm{Cl}(1.12-194.4)$ ) and Women who had history and those with contact jaundice patients (AOR $=127.6 ; 95 \% \mathrm{Cl}(12-134))$ were independently predictors of HBV.

Conclusion: Intermediate endemicity of prevalence of hepatitis HBV was detected in study area. Blood transfusion, history of Vulvar ulcer and history of contact with jaundice patient were found to be the determinant factors of sero-positivity of HBV. Awareness creation on HBV transmission and early screening of HBV at blood donation site important to reduce HBV endemicity.

\section{Introduction}

\section{Background}

Viral hepatitis is an emerging global health problem globally; approximately 350-400 million persons are chronically infected with hepatitis B virus (HBV), over 65 million of whom are in Africa. One in four people with chronic hepatitis $B$ develop serious health problems(1). Hepatitis B virus (HBV) infection is a serious public health problem in sub-Saharan Africa pregnant women(2). There are several epidemiological studies available on hepatitis B virus among pregnant women in Ethiopia. These individual studies revealed wide variation over time and across geographical areas. Up to $20 \%$ of patients who develop HBsAg sero conversion may reactivate, becoming HBeAg positive again. Thus, regular follow-up with quantitative measurement of hepatitis B virus DNA and aminotransferase levels is required after sero conversion to ensure its durability(3).prevalence of Hepatitis B virus infected pregnant women increasing and its burden was exceedingly high in Ethiopia, there is a still literature gap in study area which clearly 
shows the prevalence and associated factors of Hepatitis B virus. Hence, this study is expected to provide area-specific information for decision-makers by visualizing prevalence and its associated factors. At the same time it also fills the literature gaps in the country regarding prevalence and associated Factors of hepatitis $B$ virus.

\section{Methods}

\section{Study area}

The study were conducted in Hawassa town Hawassa University Comprehensive Specialized Hospital, Adare General Hospital one Sidama Region in Hawassa city and other Hawassa City Tula primary Hospital in Tula Sub-city. The area is located $275 \mathrm{~km}$ by road South of Addis Ababa. According to the CSA (2007), the total Population size of the town is 371,826 with male to female ratio of $191,352: 180,474$ residing in 8 sub cities. In the town there are three governmental hospital, ten heath centers under the government and one health center under non-governmental organization and five primary private hospitals, three specialized, twenty two medium clinics providing health care services to the community.

The hospital ANC clinic provides routine antenatal screening services, such as HIV testing, hemoglobin determination, blood group testing, rapid plasma testing, and urinalysis (for glucose, proteins, and infection) for more than 30,15,10 respect pregnant women per day(hospital HMIS). Hospital based Analytical cross sectional study was Hawassa University College of medicine and health science comprehensive specialized hospital, Adare General Hospital one Sidama Region in Hawassa city and Tula primary Hospital in Tula Sub-city, Antenatal clinic from May 20, 2021 to July 30, 20121

\section{Study design and study period}

Institutional based cross sectional study was conducted at Hawassa City, Antenatal clinic from May 20, 2021 to July 30,20121

\section{Population}

All pregnant women who attended routine antenatal care services in Hawassa city public Hospitals.

\section{Source population}

A source population of the study was all pregnant women who attend routine antenatal screening services.

\section{Sample size of the study}

According to a previous study done in Wolayta zone, the Prevalence of hepatitis B virus in pregnant women was $7.3 \%(2)$. This prevalence are used to calculate the minimum sample size for this study. Single 
proportion formula with $95 \%$ confidence level $(Z(1-\dot{a} / 2)=1.96)$ and $3 \%$ marginal errors will be used to determine sample size;

$$
n=z^{2} a / 2 \quad(\underline{P}(\underline{1-P})) .
$$

$d^{2}$

Where $n=$ maximum sample size

$$
\begin{aligned}
& P=7.3 \% \text { (prevalence from Previous study) } \\
& d=(0.03) \text { marginal error between sample and population } \\
& Z_{a / 2}=(1.96) \text { critical value at } 95 \% \text { confidence interval }
\end{aligned}
$$

$\mathrm{n}=(1.96)^{2} \times .073 \times .927 / 0.0009=$. By adding $10 \%$ non-respondents rate gives total sample size 320 respondents.

\section{Inclusion criteria:}

All pregnant women who are visited ANC clinic of Hawassa University College of medicine and health science comprehensive specialized hospital, Adare General Hospital Sidama Region in Hawassa city and other Hawassa City Tula primary Hospital in Tulla Sub-city in the study period and those who are volunteers are included in the study.

\section{Exclusion criteria}

Pregnant women who have gotten HBV vaccination, don't talk, mental ill and Critical sick was excluded from the study

\section{Data collection tool and collection methods}

Data was collected by face to face interview using the prepared questionnaires after four hour training given for four female nurses who has at least diploma, one laboratory technology \& laboratory technician for sample collection and testing processes. The training focused mainly on the aim of the study. On each part questionnaires that will be developed after reviewing literature will be used. To ensure data quality the data collection process will be supervised by two trained supervisors and the principal investigator at each step daily. Data was collected From June 20-July 30/2021.

The primary data sources were responses of sampled women household in which women's 15 to 49 year was respondents of the interviews. To secure accurate and complete data on prevalence and associated factors data collection tool questionnaire were adapted by reviewing different literatures and guidelines in line with the objectives of study. The tool has different parts; socio-demographic characteristics, associated factors HBV and Reproductive history. All collected serum specimens were tested for HBsAg 
using rapid diagnostic test kits according to the manufacturer's guidelines (Chromatist HBsAg rapid test from LINEAR Chemicals P.L.C). To ensure the quality of the data the following measures were undertaken. The questionnaires were designed in English. A total of four hours intensive training was given for all supervisors, data collectors and sample collectors. Data were daily checked for completeness, clarity and consistency by the supervisors and the principal investigator. Overall activity will be controlled by the principal investigator, who supervised carefully during data collection and finally data will be validated through double data entry by Epi-data 3.1 software.

\section{Operational definition}

Sero-prevalence: presence of hepatitis B virus in serum sample

Tattoo: artificial rapping of body by using sharp materials

Trimester: fetal development stage which is divided by 3 months

\section{Data processing and analysis}

Data were entered in to Statistical Package for Social Sciences (SPSS) version 25.0. To assess associated factors P-value of $<0.05$ was regarded as significant. The sero-prevalence for HBsAg among pregnant women was express in percentages for the entire study group and results are obtained presented, in tables. The statistical logistic Regression was used to determine the association between variables. (OR) and $95 \%(\mathrm{Cl})$ was used a measure of the strength of association.

\section{Data quality assurances}

The validity and completeness of the data was verified by the principal investigator daily. The performance of the rapid HBsAg test kit was evaluated using known positive and negative controls obtained from HBsAg rapid tested pregnant women. Furthermore, the formation of a color band at the control line will be acted as a procedural control and further validated the results

\section{Ethics Approval and Consent to Participate}

The study was conducted after getting approval from pharma college institutional review board (IRB) to conduct the study. A formal support letter was written to three of selected hospitals, where the study conducted. Both verbal and written consents were obtained from the study participants. For those who are unable to read and write verbal consent were obtained after explaining the purpose of the study while for those who are able to write and read, written consent were obtained. During the consent process first IRB-approved version of consent form in Amharic (the local language) language prepared. Confidentiality is keep at each step of data collection and processed. In addition, positive HBsAg test results of the study participants were communicated with their physician for farther investigation and better management of the patients. 


\section{Result}

\subsubsection{Socio - Demographic Characteristics}

A total of 326 pregnant mothers attending public health facilities of Hawassa city for ANC service were included in the study with a response rate of $98.2 \%$. Maximum and minimum age of participant was 39 and 15 respectively with the mean of 28.73 (SD \pm 6.64 years). Majority, 335(681\%) were in the age ranged from 25-29 years. The study participants predominantly 306 (95.6\%) were married. More than half of women's 306(95.6) were married. Around 131(40.9\%) were protestant religion followers. Concerning the occupation more than half 171 (53.4\%) was house wife. Regarding the educational status, $126(39.4 \%)$ of the respondents and were completed secondary school. Regarding monthly income 153(47.8) were $>3001$ (Table 1).

Table 1: Socio-Demographic Characteristics of reproductive women's of Hawassa city, Sidama region, Ethiopia 2021. 


\begin{tabular}{|c|c|c|c|}
\hline Variable & Category & Frequency & Percent (\%) \\
\hline \multirow[t]{5}{*}{ Age } & $15-19$ & 18 & 5.6 \\
\hline & $20-24$ & 88 & 27.5 \\
\hline & $25-29$ & 130 & 40.6 \\
\hline & $30-34$ & 49 & 15.3 \\
\hline & $35-39$ & 35 & 10.9 \\
\hline \multirow[t]{2}{*}{ Residence } & Urban & 243 & 75.9 \\
\hline & Rural & 77 & 24.1 \\
\hline \multirow[t]{3}{*}{ Religion } & Protestant & 131 & 40.9 \\
\hline & Orthodox & 108 & 33.8 \\
\hline & Muslim & 81 & 25.3 \\
\hline \multirow[t]{3}{*}{ Marital status } & Married & 306 & 95.6 \\
\hline & Divorced & 7 & 2.2 \\
\hline & Widowed & 7 & 2.2 \\
\hline \multirow[t]{4}{*}{ Occupation } & Governmental & 67 & 21.0 \\
\hline & House wife & 171 & 53.4 \\
\hline & Student & 43 & 13.4 \\
\hline & Merchant & 39 & 12.2 \\
\hline \multirow[t]{4}{*}{ Educational level } & No education & 31 & 9.7 \\
\hline & Primary & 95 & 29.7 \\
\hline & Secondary & 126 & 39.4 \\
\hline & More than Secondary & 68 & 21.2 \\
\hline \multirow[t]{4}{*}{ Monthly income(Birr) } & $<1000$ & 39 & 12.2 \\
\hline & $1001-2000$ & 63 & 19.7 \\
\hline & $2001-3000$ & 65 & 20.3 \\
\hline & $>3001$ & 153 & 47.8 \\
\hline
\end{tabular}




\section{Clinical factors}

From the participants included in this study $252(78.8 \%)$ have no history of tooth extraction and 295 (92.2\%) were Prancing sharped material respectively. Most, 286 (89.4\%) of women's have no tattooing. Of total participants, majority of them $306(95.6 \%)$ had no history of HIV virus and almost all of respondents 316(98.1\%) have no Yellowish Eye contact. Around 298(89.1\%) have no history of blood transfusion and $276(86.2 \%)$ have no any surgical procedures (Table 2$)$.

Table 2: Prevalence and Clinical Characteristics of reproductive women's of Hawassa city, Sidama region, Ethiopia 2021. 


\begin{tabular}{|c|c|c|c|}
\hline Variable & Category & Frequency & Percent (\%) \\
\hline \multirow[t]{2}{*}{ Hepatitis B virus } & Yes & 11 & 6.9 \\
\hline & No & 309 & 93.1 \\
\hline \multirow[t]{2}{*}{ Tooth extraction } & Yes & 68 & 21.2 \\
\hline & No & 252 & 78.8 \\
\hline \multirow[t]{2}{*}{ Surgical procedure } & Yes & 44 & 13.8 \\
\hline & No & 276 & 86.2 \\
\hline \multirow[t]{2}{*}{ Tattooing } & Yes & 34 & 10.6 \\
\hline & No & 286 & 89.4 \\
\hline \multirow[t]{2}{*}{ Prancing sharped material } & Yes & 25 & 7.8 \\
\hline & No & 295 & 92.2 \\
\hline \multirow[t]{2}{*}{ Blood Transfusion } & Yes & 35 & 10.9 \\
\hline & No & 285 & 89.1 \\
\hline \multirow[t]{2}{*}{ HIV states } & Yes & 14 & 4.4 \\
\hline & No & 306 & 95.6 \\
\hline \multirow[t]{2}{*}{ HBV Vaccinated } & Yes & 18 & 5.6 \\
\hline & No & 302 & 94.4 \\
\hline \multirow[t]{2}{*}{ More than one partner sexual participated } & Yes & 18 & 5.6 \\
\hline & No & 302 & 94.4 \\
\hline \multirow[t]{2}{*}{ History of Diabetic mellitus } & Yes & 10 & 3.1 \\
\hline & No & 310 & 96.9 \\
\hline \multirow[t]{2}{*}{ Yellowish Eye contact } & Yes & 4 & 1.3 \\
\hline & No & 316 & 98.7 \\
\hline \multirow[t]{2}{*}{ History of admitted in hospital } & Yes & 47 & 14.7 \\
\hline & No & 273 & 85.3 \\
\hline \multirow[t]{2}{*}{ Work in clinical place } & Yes & 14 & 4.4 \\
\hline & No & 306 & 95.6 \\
\hline \multirow[t]{2}{*}{ Contact with jaundice patient } & Yes & 19 & 5.9 \\
\hline & No & 301 & 94.1 \\
\hline
\end{tabular}




\section{Reproduce health factor}

From the participants included in this study, 262 (81.9\%) and 249 (77.8\%) were multi-gravid and multiPara respectively. Total participants, majority of them 180 (56.3\%) had more than two ANC follow up visit in current pregnancy. Regarding gestational age of current pregnancy, less than half of them were less than 2 nd trimester (44.7\%). Almost equal magnitude $277(86.6)$ have no history of abortion and no sexual multiple contact respectively (Table 3 ).

Table 3: Reproductive Characteristics of reproductive women's of Hawassa city, Sidama region, Ethiopia 2021. 


\begin{tabular}{|c|c|c|c|}
\hline Variable & Category & Frequency & Percent (\%) \\
\hline \multirow[t]{2}{*}{ History of gravity } & Prime gravid & 58 & 18.1 \\
\hline & Mult gravid & 262 & 81.9 \\
\hline \multirow[t]{3}{*}{ Stage of pregnancy } & $1^{\text {st }}$ trimester & 95 & 29.7 \\
\hline & $2^{\text {nd }}$ trimester & 94 & 29.4 \\
\hline & $3^{\text {rd }}$ trimester & 131 & 40.9 \\
\hline \multirow[t]{4}{*}{ Visited health facility } & One time & 62 & 19.4 \\
\hline & Two time & 78 & 24.4 \\
\hline & Three time & 96 & 30.0 \\
\hline & Four time & 84 & 26.3 \\
\hline \multirow[t]{4}{*}{ History of party } & One & 71 & 22.2 \\
\hline & Two & 84 & 26.3 \\
\hline & Three & 103 & 32.2 \\
\hline & Four & 62 & 19.4 \\
\hline \multirow[t]{2}{*}{ Caesarian section } & Yes & 55 & 17.2 \\
\hline & No & 265 & 82.8 \\
\hline \multirow[t]{2}{*}{ Abortion } & Yes & 43 & 13.4 \\
\hline & No & 277 & 86.6 \\
\hline \multirow[t]{2}{*}{ Female genital mutilation } & Yes & 184 & 57.5 \\
\hline & No & 136 & 42.5 \\
\hline \multirow[t]{2}{*}{ Vulvar Ulcer } & Yes & 15 & 4.7 \\
\hline & No & 305 & 95.3 \\
\hline \multirow[t]{2}{*}{ Sexual contact multiple partner } & Yes & 43 & 13.4 \\
\hline & No & 277 & 86.6 \\
\hline
\end{tabular}

\section{Bivariate and multivariate logistic regression analysis of factors associated to HBV}

In bivariate analysis, Tattooing, sharing sharp material, Cesarean section, history of abortion, blood transfusion, history of hospital admission, vulvar ulcer and history of contact with jaundice patient become candidate for multivariate analysis $(p<0.25)$. Among those entered in multivariate analysis, 
history of blood transfusion, vulvar ulcer and history of contact with jaundice patient were significantly associated with HBV infection among pregnant women attending ANC at public hospitals in Hawassa town. Those participants with history of blood transfusion were nearly nineteen times more likely to acquire HBV infection compared to those who didn't had history of transfusion ( $\mathrm{AOR}=18.99,95 \% \mathrm{Cl}$, (2.1-171)). Pregnant women having history of vulvar ulcer were nearly fifteen times more likely to acquire HBV infection comparing having no history of vulvar ulcer $(A O R=14.78 ; 95 \% \mathrm{Cl}(1.12-194.4))$ and Women who had history and those with contact jaundice patients $(A O R=127.6 ; 95 \% \mathrm{Cl}(12-$ 134)) were independently predictors of HBV (Table 4).

Table 4: Bivariate and multivariate analysis of factors associated with HBV pregnant of women's of Hawassa city, Sidama region, Ethiopia 2021. 
Characteristics

\begin{tabular}{lll} 
HBV status & $\mathrm{P}$ & $\mathrm{COR}(95 \% \mathrm{Cl})$ \\
\cline { 1 - 1 } Positive Negative &
\end{tabular}

$\operatorname{AOR}(95 \% \mathrm{Cl})$

\section{Tattooing}

$\begin{array}{lcccccc}\text { Yes } & 8 & 26 & 0.00 & 6[2.29-15.6] & 0.05 & 6.9[0.98-48.7]^{*} \\ \text { No } & 14 & 272 & & 1 & \\ \begin{array}{l}\text { Sharing sharp } \\ \text { material }\end{array} & 10 & 15 & 0.00 & \begin{array}{l}15.7[5.86- \\ 42.2]\end{array} & 0.4 & 2.43[0.3-19]^{*} \\ \text { Yes } & 12 & 283 & & 1 & \\ \text { No } & & & & 1\end{array}$

Caesarian section

$\begin{array}{lllllll}\text { Yes } & 13 & 42 & 0.00 & \begin{array}{l}8.86[3.54- \\ 21.88]\end{array} & 0.05 & 8.3[0.99-69.5]^{*} \\ \text { No } & 9 & 256 & & & \end{array}$

\section{Abortion}

Yes

$7 \quad 36$

0.13

$3.46[1.3-8.89]$

0.13

$6.4[0.58-72]^{\star}$

No

15
262 1

Blood transfusion

Yes 14

21

0.00

236[8.7-61.2]

0.00

$19[2.1-171]^{\star *}$

No

$8 \quad 277$

1

Hospital admission

Yes

12

35

0.00

9[3.63-22.5]

0.9

$0.88[0.09-8.4]^{\star}$

No

10

263

1

Vulvar ulcer

Yes

No

$8 \quad 7$

$14 \quad 291$

0.00

23.76[7.54-
74.83]

0.04

$14.78[1.12-$ 291

1

Contact jaundice

patient

Yes

No

$\begin{array}{llllll}14 & 5 & 0.00 & 102.6[29.7- & \mathrm{p}= & 127.6[12.1- \\ & & & 354.1] & 0.00 & 134.5]^{\star \star}\end{array}$

$8 \quad 293$

1 
$\mathrm{AOR}=$ adjusted odds ratio, $\mathrm{COR}=$ crude odds ratio

$*=<0.25 \quad * *=<0.05$

\section{Discussion}

The aim of this study was to access prevalence and associated factors of hepatitis $B$ virus in pregnant women's of Hawassa town, Sidama region. In this study, the overall prevalence of HBV in the study area was $6.9 \%$. The study revealed that blood transfusion, vulvar ulcer and history of contact jaundice were remained as major predictors of HBV prevalence. This shows a level of endemicity of HBV infection qualifying as almost intermediate according to the criteria of the World Health Organization (4).

The current prevalence was lower than different countries reports which is Cameroon 25.3\% (5), Gambia 9.20\%(6), Ghana7.7\%(7) and higher than research done in Rwanda with prevalence of HBV $3.7 \%$ (8) , Turkey $2.1 \%(9)$. This prevalence rate is higher than different regions of Ethiopia which has been reported West Hararge public hospital 6.1\% (1) Another study done in Amhara region and Addis Ababa shows that prevalence in Amhara region and $1 \%$ (10) in Addis Ababa city was $36 \%$ respectively. and lower than study from Southern Ethiopia, Gedeo Zone prevalence of 9.2\%(11).

The prevalence of HBV infection among pregnant mothers in Addis Ababa was 7\%(12) which is approximately similar with the current finding higher than other city Bahir Dar 4.7\%(13) and West Hararge $6.1 \%(1)$ The prevalence was lower than that of a research conducted in Ethiopia's Gambela region in case prevalence was $7.9 \%$ (14). The variation in prevalence could be due to difference in geographical, socio cultural and behavioral factors of study participants. The study revealed that, vulvar ulcer and history of contact jaundice were remained as major predictors of HBV prevalence.

In this study, participants with blood transfusion three times more likely to acquire HBV infection, [AOR = $19,95 \% \mathrm{Cl}=[2.1-171] \mathrm{p}=0.004]$. This finding goes in line with study conducted at Hargeisa, Somaliland (15) but contradicted by study conducted at Weast Harerege history of abortion, traditional tonsillectomy (tonsillectomy conducted by an untrained practitioner), admission to a health facility , multiple sexual partners were associated with hepatitis B virus infection among pregnant women(1) and Gambela shows that history of abortion, occupation and multiple sexual partner are the major factors associated with $\mathrm{HBV}(14)$.

History of Pregnant women having history of vulvar ulcer were showed statistically significant association with HBV infection this study which is similar with study done Somaliland (15) and contradicts with finding from Wolayita zone southern Ethiopia in which HBV be linked to body fluids, semen and vaginal secretions(2).

HBV infection was highly related with history of contact jaundice 127.6 [12.1-134.5, $p=0.00]$ which is congruent with research done in Mizan Aman Southwest Ethiopia History of contact with jaundice patients was significantly associated(16). 


\section{Conclusion}

Intermediate endemicity of prevalence of hepatitis HBV was detected among pregnant women attending ANC in Hawassa city public hospitals according to WHO classification. Blood transfusion, history of Vulvar ulcer and history of contact with jaundice patient were found to be the determinant factors of seropositivity of HBV.

\section{Recommendations}

Recommendation based on the study finding, the following recommendations were forwarded to concerned bodies in order to reduce transmission of HBV from the mother to child and its consequences.

- Health education programs on the mode of HBV transmission, especially on prevention of contact with jaundice patients.

- Early screening on blood before blood donation and transfusion were suggested

- Reduction of high-risk behaviors including having unprotected contact with vulvar ulcer and methods of preventions should be given to communities as well as to ANC attendants at antenatal care clinics to raise the awareness of mothers and community.

- It is also advisable to implement to screen blood donation to prevent HBV transmission at blood bank and transfusion site.

- Further study should be performed by using more sophisticated diagnostic methods like ELISA, molecular HBV- Deoxyribonucleic acid test.

\section{Strength And Limitations Of The Study}

- Study involved specialized, General hospitals and districts hospitals it is good to estimate pooled prevalence in city

- Laboratory technologists performed all testing blinded through use of coded specimens.

- Since study involved multicenter so it have appropriate sample size and it can explain real prevalence comparison to single site study

- It is cross sectional design goes it does not measure cause and effect of relationship.

- Number of positives are few that can may weak the association of predictor

\section{Abbreviations}

CLD: $\quad$ Chronic Liver Disease

DNA: Dianiculic Acid

DHBV: $\quad$ Duck Hepatitis B virus 
HBsAg: Hepatitis B Surface antigen

HCC: $\quad$ Hepatocellular Carcinoma

HHBV: $\quad$ Heron hepatitis B virus

HIV: $\quad$ Human Immunovires

GSHV: $\quad$ Ground Squirrel Hepatitis B virus

NPC: $\quad$ Nuclear Pore Complex

\section{Declarations}

\section{Ethics Approval and Consent to Participate}

The study was conducted after getting approval from pharma college institutional review board (IRB) to conduct the study. A formal support letter was written to three of selected hospitals, where the study conducted. Both verbal and written consents were obtained from the study participants. For those who are unable to read and write verbal consent were obtained after explaining the purpose of the study while for those who are able to write and read, written consent were obtained. During the consent process first IRB-approved version of consent form in Amharic (the local language) language prepared. Confidentiality is keep at each step of data collection and processed. In addition, positive HBsAg test results of the study participants were communicated with their physician for farther investigation and better management of the patients.

Consent to publish: Not applicable.

Availability of data and materials: For those who are interested the datasets analyzed during the current study are available from the corresponding author on reasonable request.

Competing interests: The authors declare that they have no competing interests.

Funding: Not applicable

Authors Contribution: $\mathrm{BB}, \mathrm{MB}$, conceived and designed the study and developed the data collection instruments. $\mathrm{BB}$ and $\mathrm{MB}$ performed the statistical analysis and wrote all versions of the manuscript. All authors critically revised and approved the final manuscript.

Acknowledgment: we would like to say thank you very much for all mothers who are involved as study participant in this study.

\section{References}


1. Mamuye B, Gobena T, Oljira L. Hepatitis B virus infection and associated factors among pregnant women attending antenatal clinics in west hararghe public hospitals, oromia region, Ethiopia. Pan Afr Med J. 2020;35:1-9.

2. Bancha B, Kinfe AA, Chanko KP, Workie SB, Tadese T. Prevalence of hepatitis B viruses and associated factors among pregnant women attending antenatal clinics in public hospitals of Wolaita Zone, South Ethiopia. PLoS One [Internet]. 2020;15(5):1-12. Available from:

http://dx.doi.org/10.1371/journal.pone.0232653

3. Ocama P, Opio CK, Lee WM. Hepatitis B virus infection: Current status. Am J Med. 2005;118(12):1413.e15-1413.e22.

4. Alemu AY, Endalamaw A, Belay DM, Mekonen DK, Birhan BM, Bayih WA. Healthcare-associated infection and its determinants in Ethiopia: A systematic review and meta-analysis. PLoS One. 2020;15(10 October 2020).

5. Awole M, Gebre-Selassie S. Seroprevalence of HBsAg and its risk factors amoung pregnant women in Jimma, Southwest Ethiopia. Ethiop J Heal Dev. 2005;19(1).

6. Bittaye M, Idoko P, Ekele BA, Obed SA, Nyan O. Hepatitis B virus sero-prevalence amongst pregnant women in the Gambia. BMC Infect Dis. 2019;19(1):1-8.

7. Dortey BA, Anaba EA, Lassey AT, Damale NKR, Maya ET. Seroprevalence of Hepatitis B virus infection and associated factors among pregnant women at Korle-Bu Teaching Hospital, Ghana. PLoS One [Internet]. 2020;15(4):1-10. Available from: http://dx.doi.org/10.1371/journal.pone.0232208

8. Makuza JD, Rwema JOT, Ntihabose CK, Dushimiyimana D, Umutesi J, Nisingizwe MP, et al. Prevalence of hepatitis B surface antigen (HBsAg) positivity and its associated factors in Rwanda. BMC Infect Dis. 2019;19(1):1-10.

9. Cetin S, Cetin M, Turhan E, Dolapcioglu K. Seroprevalence of hepatitis B surface antigen and associated risk factors among pregnant women. J Infect Dev Ctries. 2018;12(10):904-9.

10. Yazie TD, Tebeje MG. An updated systematic review and meta-analysis of the prevalence of hepatitis B virus in Ethiopia. BMC Infect Dis. 2019;19(1):1-13.

11. Tadiwos MB, Kanno GG, Areba AS, Kabthymer RH, Abate ZG, Aregu MB. Sero-Prevalence of Hepatitis B Virus Infection and Associated Factors Among Pregnant Women Attending Antenatal Care Services in Gedeo Zone, Southern Ethiopia. J Prim Care Community Heal. 2021;12.

12. Metaferia Y, Dessie W, Ali I, Amsalu A. Seroprevalence and associated risk factors of hepatitis B virus among pregnant women in southern Ethiopia: a hospital-based cross-sectional study. Epidemiol Health. 2016;38:e2016027. 
13. Gedefaw G, Waltengus F, Akililu A, Gelaye K. Risk factors associated with Hepatitis B virus infection among pregnant women attending antenatal clinic at Felegehiwot referral hospital, Northwest Ethiopia, 2018: An institution based cross sectional study. 2019;1-14.

14. Tanga AT, Teshome MA, Hiko D, Fikru C, Jilo GK. Sero-prevalence of hepatitis B virus and associated factors among pregnant women in Gambella hospital, South Western Ethiopia: Facility based cross-sectional study. BMC Infect Dis. 2019;19(1):1-7.

15. Al-Mamari* A. Determine seroprevalence and associated risk factors of HBV infection among pregnant women and it relationship with blood transfusion at Hargeisa Group Hospital, Hargeisa, Somaliland. Int J Clin Virol. 2019;001-9.

16. Asaye Z, Aferu T, Asefa A, Feyissa D, Regasa T, Kebede O, et al. Prevalence of hepatitis b virus among pregnant women on antenatal care follow-up at mizan-tepi university teaching hospital and mizan health center, southwest ethiopia. Int J Gen Med. 2021;14:195-200. 